\title{
PENERAPAN SPATIAL MASK UNTUK PEMBENTUKAN EFEK SEPIA PADA CITRA DIGITAL DENGAN MODIFIKASI NILAI PIKSEL
}

\author{
Faruk Alfiyan \\ Program Studi Teknik Informatika \\ STIKOM PGRI Banyuwangi; Jl. Ahmad Yani, 80 Banyuwangi, Telp/Fax 0333417902 \\ Email: farukalfiyan@gmail.com
}

\begin{abstract}
ABSTRAK
Efek Sepia adalah sebuah efek yang mengarah pada warna hitam putih berbaur dengan warna kecoklatan, sehingga akan tampak seperti foto yang sudah lama dicetak. Saat ini penggunaan efek sepia sudah merambah hampir semua bidang khidupan manusia, mulai dari industri iklan, film, animasi, multimedia, hingga media sosial. Dalam penelitian ini akan dilakukan analisa apakah penerapan algoritma spatial mask yang dikombinasikan dengan modifikasi pada tiap mask RGB yang ada dalam sebuah citra akan dapat menghasilkan efek sepia pada citra digital. Dari hasil penelitian ini diharapkan akan dapat memberikan gambaran pada penelitian selanjutnya, terutama penelitian yang berhubungan dengan efek sepia citra digital sehingga hasil yang diperoleh dapat lebih maksimal.
\end{abstract}

Kata Kunci: Sepia, Spatial, Mask, Citra, Digital

\begin{abstract}
Sepia effect is an effect that leads to the black and white colours blend with colors brownish, so it will look like the photo that had long been out of print. The current use of sepia effect already penetrated virtually all areas of human life, from the advertising industry, movies, animation, multimedia and social media. In this research will be conducted an analysis of whether the application of the algorithm of spatial mask combined with modifications to each existing RGB mask in an image will be able to produce a digital image on a sepia effect. From the results of this research are expected to be able to give an overview on the research afterwards, especially research related to the effects of sepia image of digital so that the results obtained can be more optimally.
\end{abstract}

Keywords: Sepia, Spatial, Mask, Image, Digital 


\section{PENDAHULUAN}

Kemajuan teknologi komputer telah dapat mentransformasi segala bentuk fisik ke dalam bentuk digital. Digitalisasi memungkinkan adanya manipulasi informasi termasuk pada foto. Sepia adalah salah satu proses foto yang menambahkan tone ke foto hitam putih untuk memberikan kesan yang lebih hangat (Seegehalli, 2016). Tujuan membuat foto sepia pada awalnya adalah supaya foto hitam putih terlihat lebih menarik, dan juga difungsikan untuk mengawetkan foto, karena unsur kimia yang ditambahkan ke dalam foto dapat memperpanjang umur foto. Namun di era fotografi digital, efek foto sepia sudah tidak lagi difungsikan untuk mengawetkan foto, tapi lebih untuk memberi kesan nostalgia (Partala, Fylakis, Pramila, Keskinarkaus, \& Seppänen, 2016). Secara visual foto sepia lebih terkesan seperti foto yang sudah tua usianya sehingga lebih cocok jika obyek fotonya juga obyek yang berusia tua pula, misalnya mobil tua, orang tua, kebudayaan tradisional, bangunan tua, dan sejenisnya. (Riyadi, 2015)

Perkembangan teknologi informatika telah merambah berbagai bidang kehidupan manusia. Salah satu contoh dari efek perkembangannya adalah adanya proses digitalisasi. Dengan proses digital, berbagai macam bentuk fisik dapat dimanipulasi dengan mudah sehingga dapat menghasilkan suatu informasi yang baru. Sebelum ditemukannya konsep digital dalam dunia fotografi, hampir dapat dikatakan mustahil sebuah foto dapat di edit sesuai kebutuhan editornya.

Koordinat dari sebuah piksel awalnya hanya dapat digunakan untuk menyatakan besar intensitas citra untuk suatu tingkat keabuan. Dalam perkembangannya dilakukan pemilahan menjadi tiga mask, dimana tiap-tiap mask mewakili tingkat keabuan yang berbeda, sehingga sangat dimungkinkan nilai yang terdapat dalam sebuah piksel dimodifikasi untuk kepentingan tertentu. (Gonzalez, Woods, \& Eddins, 2013).

Dalam setiap piksel citra digital sekurang-kurangnya terdapat tiga mask yang terdiri dari Red, Green, Blue. (Poblete-Echeverría, Olmedo, Ingram, \& Bardeen, 2017). Penggabungan dari ketiga mask inilah yang kemudian akan menghasilkan sebuah citra digital. (Yamashita, Sugimura, \& Hamamoto, 2015). Dengan kata lain 
jika ketiga mask tersebut dipilah menjadi tiga bagian maka akan dapat dilakukan modifikasi nilai yang ada di dalam masing-masing mask. Dengan modifikasi yang tepat akan dapat dihasilkan suatu citra baru sesuai dengan kebutuhan sang editor. Penelitian ini akan difokuskan pada modifikasi nilai piksel dari ekstrak mask yang terdapat dalam citra digital, sehingga akan menghasilkan suatu citra digital yang memiliki efek sepia secara maksimal.

\section{METODE PENELITIAN}

Urutan langkah-langkah yang ditempuh dalam penelitian ini ditunjukkan dalam blok diagram sebagaimana Gambar 1 berikut:

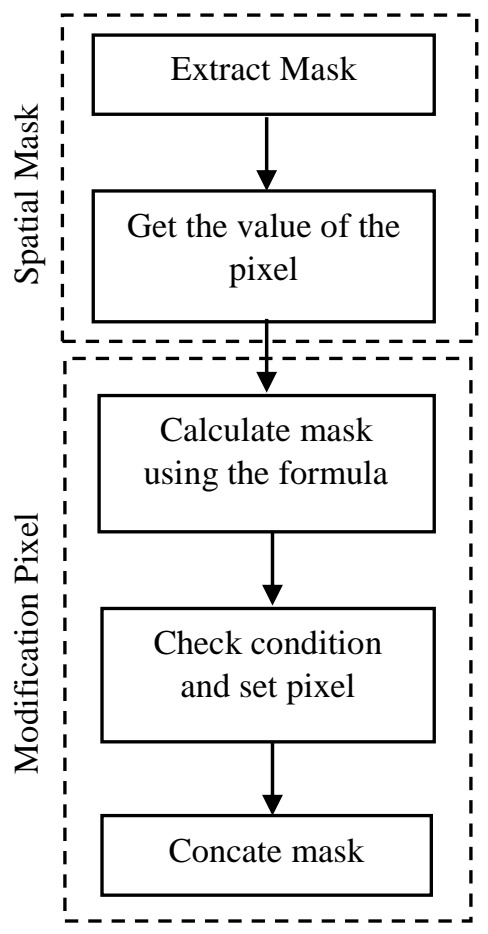

Gambar 1. Blok diagram penelitian.

Secara garis besar tahapan yang dilakukan dalam penelitian ini terbagi menjadi dua tahapan, yaitu spatial mask, dan modification pixel. Adapun penjabaran secara rinci dari blok diagram pada Gambar 1 adalah sebagai berikut: 


\section{Spatial Mask}

Spatial mask adalah suatu algoritma yang digunakan untuk memisah mask dari sebuah piksel RGB menjadi beberapa mask, yaitu red, green, dan blue. Pemisahan mask ini dimaksudkan untuk mendapatkan nilai dari masing-masing mask, sehingga nilai-nilai tersebut dapat dimodifikasi sesuai kebutuhan (Hadi, 2016). Representasi dari spatial mask dapat dilihat pada Persamaan (1) berikut:

$$
f(x, y)=\left[\begin{array}{l}
f_{r}(x, y) \\
f_{g}(x, y) \\
f_{b}(x, y)
\end{array}\right]=\left[\begin{array}{l}
r(x, y) \\
g(x, y) \\
b(x, y)
\end{array}\right]
$$

dimana untuk citra dengan ukuran $\mathrm{Mx} \mathrm{N}$, maka $\mathrm{x}=0,1,2, \ldots \mathrm{M}-1$, dan $\mathrm{y}=$ $0,1,2, \ldots \mathrm{N}-1$. Dari Persamaan (1) tersebut akan didapat turunan persamaannya sebagaimana ditunjukkan Persamaan (2) berikut :

$$
f_{r}=\frac{r}{r+g+b} ; f_{g}=\frac{g}{r+g+b} ; f_{b}=\frac{b}{r+g+b}
$$

\section{Modification Pixsel}

Tahap modification pixel ini diawali dengan memasukkan nilai piksel dari masing mask red, green, dan blue yang diperoleh melalui proses spatial mask ke dalam sebuah formula yang digunakan untuk membentuk efek sepia pada citra digital. Representasi dari formula tersebut dapat dilihat pada Persamaan (3) berikut:

$$
\begin{aligned}
& f_{r}(x, y)=\left(n_{r}(x, y) * r(x, y)\right)+\left(n_{r}(x, y) * g(x, y)\right)+\left(n_{r}(x, y) * b(x, y)\right) \\
& f_{g}(x, y)=\left(n_{g}(x, y) * r(x, y)\right)+\left(n_{g}(x, y) * g(x, y)\right)+\left(n_{g}(x, y) * b(x, y)\right)(3) \\
& f_{b}(x, y)=\left(n_{b}(x, y) * r(x, y)\right)+\left(n_{b}(x, y) * g(x, y)\right)+\left(n_{b}(x, y) * b(x, y)\right)
\end{aligned}
$$

Setelah dilakukan perhitungan pada setiap mask dengan formula sebagaimana tersebut dalam Persamaan (3), maka akan dilakukan pengecekan apakah nilai yang dihasilkan lebih besar dari 255 atau tidak. Jika nilai yang dihasilkan melebihi 255 maka nilai yang digunakan dalam mask adalah 255. Jika tidak melebihi, maka nilai tersebut langsung dijadikan nilai mask, sebagaimana ditunjukkan Persamaan (4) berikut : 


$$
\begin{aligned}
& \text { if } f_{r}(x, y)>255 \text { then } r(x, y)=255 \text { else } r(x, y)=f_{r}(x, y) \\
& \text { if } f_{g}(x, y)>255 \text { then } g(x, y)=255 \text { else } g(x, y)=f_{g}(x, y) \\
& \text { if } f_{b}(x, y)>255 \text { then } r(x, y)=255 \text { else } b(x, y)=f_{b}(x, y)
\end{aligned}
$$

Proses berikutnya adalah melakukan seting nilai piksel dimana nilai yang diambil dari setiap hasil perhitungan mask adalah nilai integernya. Dengan kata lain jika perhitungan dari formula tersebut menghasilkan nilai desimal, maka hanya nilai bulatnya yang digunakan.

Adapun proses terakhir adalah melakukan penyatuan kembali seluruh mask yang telah di extact sebelumnya, sehingga akan didapatkan nilai piksel baru sebagai dampak dari modifikasi nilai piksel dari masing-masing mask, sebagaimana ditunjukkan Persamaan (5) berikut :

$$
f_{o}(x, y)=f_{r}(x, y)+f_{g}(x, y)+f_{b}(x, y)
$$

\section{HASIL DAN PEMBAHASAN}

Untuk mengetahui tingkat keberhasilan dari penelitian ini maka perlu dilakukan uji coba, dimana dalam uji coba ini sebuah citra akan diproses dalam beberapa tahapan sesuai dengan tahapan yang telah dijelaskan dalam blog diagram penelitian.

\section{Spatial Mask}

Pada tahap ini yang dilakukan adalah mengextract piksel citra digital menjadi tiga buah mask yaitu red, green, dan blue dengan menggunakan Persamaan (1) dan Persamaan (2), sehingga diperoleh hasil sebagaimana ditunjukkan Gambar 2 berikut 


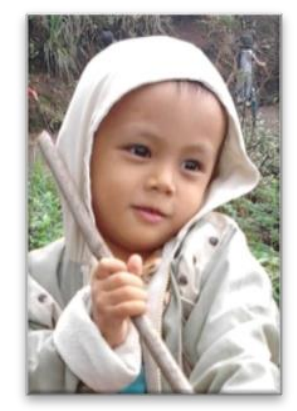

(a)

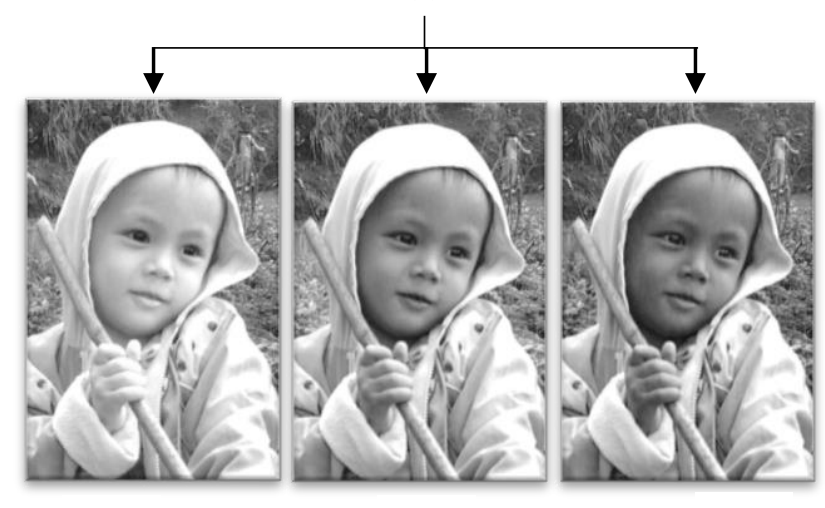

(b)

(c)

(d)

Gambar 2. : Proses spatial mask

(a) Citra input, (b) Red mask (c) Green mask (d) Blue mask

Pemecahan mask piksel ini dilakukan untuk mendapatkan nilai dari masing-masing piksel disetiap maskernya. Nilai piksel dari tiap mask inilah yang akan dijadikan acuan proses modifikasi piksel untuk memberikan efek sepia pada citra digital.

\section{Modification Pixel}

Pada tahap ini yang dilakukan adalah merubah nilai piksel dari masingmasing mask. Perubahan nilai ini diperoleh dengan memasukkan nilai dari setiap piksel mask ke dalam Persamaan (3) dan Persamaan (4), sehingga diperoleh hasil sebagaimana ditunjukkan Tabel 1 berikut : 
Tabel 1 : Modifikasi piksel

\begin{tabular}{|c|c|c|}
\hline Mask & Spatial Mask & $\begin{array}{c}\text { Modification } \\
\text { Pixel }\end{array}$ \\
\hline Red & & \\
\hline Green & & \\
\hline Blue & & \\
\hline
\end{tabular}

Modifikasi nilai piksel ini difungsikan untuk mendapatkan nilai piksel baru dari setiap mask citra, dimana nilai piksel setiap mask akan mempunyai pengaruh yang sangat besar untuk pembentukan efek sepia

Setelah didapatkan nilai piksel yang baru dari tiap-tiap mask, maka langkah selanjutnya adalah melakukan penggabungan nilai dari seluruh piksel yang terdapat dalam tiap-tiap mask citra menjadi satu kesatuan dengan menggunakan Persamaan (5) sehingga akan diperoleh hasil sebagaimana ditunjukkan Gambar 3 berikut : 


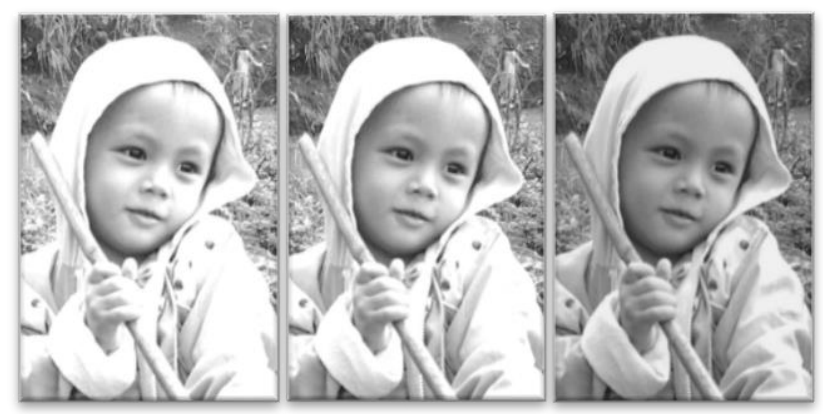

(a)

(b)

(c)

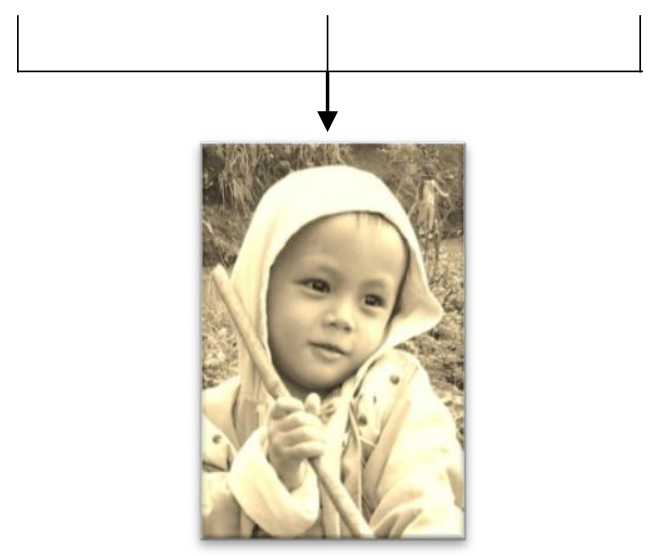

(d)

Gambar 3 : Concate mask

(a) Red mask modification, (b) Green mask modification

(c) Blue mask modification (d) Hasil

Penggabungan seluruh nilai piksel yang terdapat dalam setiap mask citra digtal inilah yang menghasilkan suatu bentuk citra baru dengan efek sepia.

Untuk melihat tingkat keberhasilan dan untuk memastikan apakah semua persamaan yang digunakan dalam metode penelitian ini dapat menghasilkan efek sepia pada semua citra, maka perlu dilakukan uji coba terhadap beberapa citra digital dengan kondisi brightness maupun contrass yang berbeda. Adapun hasil dari uji coba tersebut dapat dilihat pada Tabel 2 berikut : 
Tabel 2 : Hasil uji coba

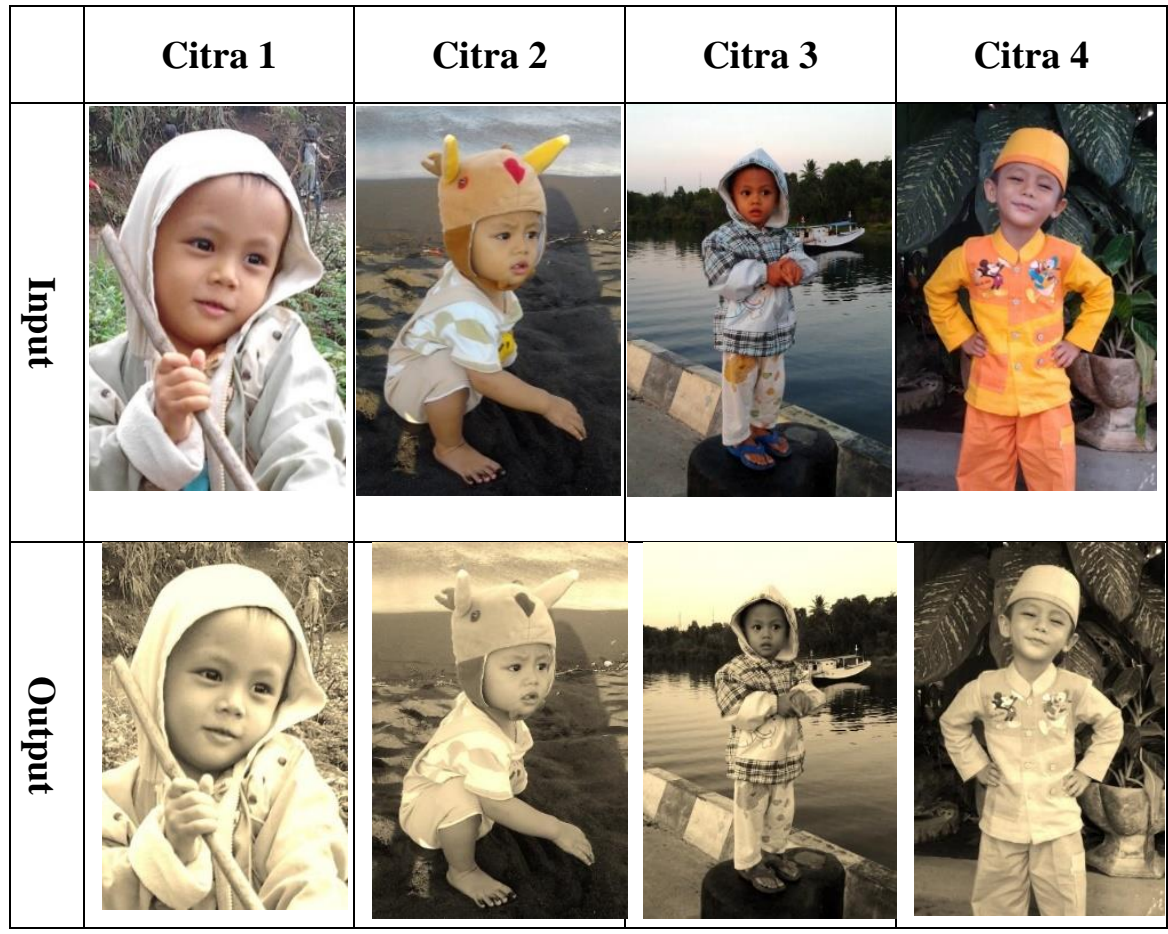

Keempat citra digital yang dijadikan bahan uji coba pada Tabel 2 terdiri dari beberapa citra yang memiliki tingkat illuminasi berbeda. Setelah diproses dengan menggunakan metode yang digunakan dalam penelitian ini, semuanya membentuk sebuah citra baru dengan efek sepia.

\section{KESIMPULAN DAN SARAN}

Dari seluruh rangkaian penelitian yang telah dilakukan maka dapat disimpulkan bahwa modifikasi nilai piksel yang terdapat pada setiap mask yang dihasilkan dari penerapan spatial mask dalam sebuah citra dapat digunakan untuk membentuk efek sepia pada citra digital.

\section{DAFTAR PUSTAKA}

Gonzalez, R. C., Woods, R. E., \& Eddins, S. L. (2013). Digital Image Processing Using Matlab - Gonzalez Woods \& Eddins.pdf. Education.

Hadi, A. K. (2016). Detection and Discrimination for Shadow of High Resolution 
Satellite Images by Spatial Filter. Journal Iraqi of Science, 57(1), 785-791.

Partala, J., Fylakis, A., Pramila, A., Keskinarkaus, A., \& Seppänen, T. (2016). Improving Robustness of Biometric Identity Determination with Digital Watermarking. Journal of Electrical and Computer Engineering, 2016, 1-9.

Poblete-Echeverría, C., Olmedo, G. F., Ingram, B., \& Bardeen, M. (2017). Detection and segmentation of vine canopy in ultra-high spatial resolution RGB imagery obtained from Unmanned Aerial Vehicle (UAV): A case study in a commercial vineyard. Journal Remote Sens, 9(3), 1-14.

Riyadi, T. (2015). Media Televisi Untuk Memudahkan Merancang Komunikasi Visual Yang Tepat. Jurnal Humaniora, 1, 705-712.

Seegehalli, P. J. (2016). Digital Eye Strain Reduction Techniques: A Review. International Journal on Computer Science and Engineering (IJCSE), 8(3), 94-100.

Yamashita, H., Sugimura, D., \& Hamamoto, T. (2015). Enhancing low-light color images using an RGB-NIR single sensor. Journal Visual Communications and Image Processing (VCIP), 2-5. 